\title{
The Research and Applications of Remaining Oil Potential Tapping in High Watered Stage for Heavy Oil Reservoir in Bohai
}

\author{
Junting Zhang*, Zongbin Liu, Lilei Wang, Zhou Fang, Jingfu Deng \\ Bohai Oilfield Research Institute of CNOOC Ltd.-Tianjin Branch, Tianjin, China \\ Email: *zhangjt26@cnooc.com.cn
}

How to cite this paper: Zhang, J.T., Liu, Z.B., Wang, L.L., Fang, Z. and Deng, J.F. (2018) The Research and Applications of Remaining Oil Potential Tapping in High Watered Stage for Heavy Oil Reservoir in Bohai. Journal of Geoscience and Environment Protection, 6, 10-21. https://doi.org/10.4236/gep.2018.69002

Received: July 26, 2018

Accepted: August 26, 2018

Published: August 29, 2018

Copyright $\odot 2018$ by authors and Scientific Research Publishing Inc. This work is licensed under the Creative Commons Attribution International License (CC BY 4.0).

http://creativecommons.org/licenses/by/4.0/

\begin{abstract}
$S$ oil field is a typical of water injection development of heavy oil reservoir in Bohai, and the formation of crude oil viscosity is $42-284 \mathrm{mPa} \cdot \mathrm{s}$. Due to the formation of crude oil viscosity, the oil field development gradually faces a series of problems as rapid rise of water cut, rapid decline of output, high water cut of oil wells and others. In order to improve the effect of oilfield development, it is necessary to increase the output of the oilfield by adjusting wells for the potential in the oilfield. However, due to the high cost of drilling, operation and testing of offshore oilfields, offshore oilfields require more elaborate description of residual oil and adjustment wells. With the continuous downturn in international oil prices and the lack of new testing data in old oilfields, it is urgent to re-use the existing data in oilfields through innovative methods to achieve a detailed description of the remaining oil in the oilfields and improve the precision research of indexing wells and ensure the reliable implementation of adjustment wells. Based on the existing dynamic data of $\mathrm{S}$ oilfield, this paper proposes a new method to quantitatively evaluate water flooding coefficient by using tracer theory to establish tracer data, and quantitatively evaluates the vicinity of the fault by means of image reflection and potential superposition and find the residual oil in the imperfect area of the well network, combined with the numerical simulation method to realize the fine description of remaining oil and improve the research precision of the adjustment well. Through the research in this paper, $S$ oilfield has proposed to location of six adjustment wells which has implemented two. The production confirmed that the method of this paper has some reliability, while the method of heavy oil in the high water cut stage of residual oil fine description. The research of enhanced oil recovery in the stage has certain guiding significance for heavy oil reservoirs.
\end{abstract}




\section{Keywords}

Heavy Oil Reservoir, Tracer Material, Sweep Efficiency, Bohai, Remaining Oil Description

\section{Introduction}

Bohai is rich heavy oil in resources. After years of practice in offshore heavy oil development, it is proved that heavy oil reservoirs can also be effectively produced by conventional water injection. Due to its simple process and low cost of water flooding, it is a widely used secondary oil recovery method in petroleum industry at present. However, due to the high viscosity of heavy crude oil and large water-oil flow ratio, in the development process, moisture rises rapidly and oil production diminishes which affecting the reservoir development effect. Through research and analysis, at present, the author improves development of heavy oil reservoirs in the high water cut stage mainly through injection-recovery structure, stuck plugging, injection on profile adjustment as well as potential adjustment well [1]-[13]. However, with the international oil price downturn, it is required to study the potential tapping potential of the oilfield more elaborately, and the detailed description of remaining oil is particularly important. The fine study of remaining oil can provide technical guidance and help for well implementation. This paper takes $S$ heavy oil reservoir in Bohai as an example, aiming at the problems which the oilfield is in high water cut stage, all layers of oil well have seen water, low productive and inefficient wells and shut down wells to study the remaining oil potential in the high water-cut stage and formulate technical solutions to enhance oil recovery. Through the theory of percolation to evaluate water flooding factor and characterize the remaining oil reserves quantitatively, it is practical to achieve the remaining oil refinement in the high water cut stage. This method has been proved to be reliable based on success of adjustment wells' production. Under the condition of low oil price, this method is further applied to combine low productivity and low efficiency wells and shut-in wells to implement side-drills to achieve the purpose of cost reduction and efficiency increase. This paper provides technical methods for fine potential residual oil in high water cut stage of Bohai heavy oilfields and provides technical ideas for oil recovery enhancement.

\section{S Oilfield Overview and Problems}

The $S$ oilfield is a typical water flooding heavy oil reservoir in the Bohai Bay. The oilfield has been put into operation in September 2005. At present, the oilfield produces 820 cubic meters per day and has a combined water content of $79 \%$. The oil recovery rate is $6.2 \%$. At present, the oilfield is in a stage of high water cut. How to further improve the oilfield development effect and achieve the recovery rate is a difficult problem the oilfield facing. 
Because of the high oil viscosity, the $\mathrm{S}$ oilfield has been raised rapidly after put into production, and the initial water content of the oilfield reached $30 \%$. After eight months of production, the water content reached $60 \%$, and the output of the oil field decreased rapidly due to the rapid rise of water cut. As the development time prolongs, the dynamic data increase gradually. According to the data of oil well production profiles, it is confirmed that all the layers of the oil well have seen water and reach the high water cut stage. The remaining oil is difficult to find. At present, the reliance on numerical modeling alone cannot ensure the refinement and accuracy of the remaining oil research. As it is more difficult to find potential, it is imperative to adopt technological innovation and demonstrate the remaining oil reserves by various methods to improve the accuracy of adjustment wells and provide a more reliable basis for the implementation. Due to the viscosity of crude oil, there are low-yielding oil wells and shut-down wells, leading to the potential of the oil field cannot be released, the recovery degree is low and the current oil production is only $6.2 \%$. In order to further excavate the potential and improve the oilfield development effect, it is very important to describe the remaining oil finely in the high water cut stage. Therefore, it is necessary to study the remaining oil and combine the research results with the low-yield and low-efficiency wells and shut-down wells effectively to find the potential adjustment wells and side-drilled wells to increase the oil recovery rate so as to reduce the costs and increase the efficiency.

\section{The New Technology of Remaining Oil Fine Description}

The S oilfield and oil well layers all reach the stage of high water cut, and the remaining oil distribution location and remaining oil reserves are difficult to determine.

Based on the existing problems, this paper analyzes the dynamic and static data of S oilfield, uses the theory of tracer and seepage theory to innovatively apply the dynamic data, establishes the quantitative evaluation of tracer quantitatively and characterizes remaining oil. Through theoretical research combined with numerical simulation method, the residual oil can be finely portrayed to lay a material foundation for finding potential in the oilfield.

\subsection{Quantitative Evaluation of Water Flooding Sweep Efficiency Based on Tracer Data}

Tracer technology is an effective way to verify the connectivity of oil and water wells in water flooding oilfields. In recent years, a series of field experiments have been conducted around the world to form a relatively complete theoretical system. The basic principle of tracer technology is referring to the dynamic and static data of the test well group and the test scheme which adds tracer into the injection wells and takes samples from the surrounding production wells, performs tracer analysis in the laboratory and obtains the tracer content then draw the tracer production curve of the production wells. According to the curve of 
see tracer concentration in wells around, the information such as the direction and speed of the injected fluid can be further confirmed, and the connectivity between oil and water wells can be visually given.

The well A24 in the S oilfield verified the connectivity between oil-water through tracer technology. According to the changes in the concentrations of the surrounding wells, it can be seen that the well A24 is in communication with surrounding wells.

After seeing the tracer in wells, with the extension of production time, concentration changes gradually from the local concentration to peak, and then reduced to the local concentration, showing a normal distribution. The process mainly shows the tracer flows out from the injection end to the exit end and the concentration changes as the change of the number of flow lines from the injection end to the exit end.

Based on the existing tracer test data, the connectivity between oil and water wells can be visually presented. At the same time, according to the tracer flow theory, through the technological innovation and using tracer theory combined with programming methods to achieve tracer flow law described. According to the change of the number on flow lines in different oil wells, the extent of oil well affected by injection well can be determined, and the water flooding coefficient can be quantitatively given. Further analysis is made on the flooding of oil wells effect by injection wells, the remaining oil concentration area can be determined, and the direction of potential is clarified.

Based on the theory of tracer [14] [15] and the theory of percolation, the establishment of oil-water two-phase flow equation, tracer concentration diffusion equation, wellbore output concentration variation equation and the water front law equation are established, as shown in Formulas (1)-(5).

The two-phase oil-water continuity equation is established, as shown in Equation (1):

$$
\begin{aligned}
& \nabla \cdot\left[\frac{k k_{r o}}{B_{o} \mu_{o}}\left(\nabla p_{o}-\rho_{o} g \nabla D\right)\right]-\frac{q_{o}}{\rho_{o s c}}=\frac{\partial}{\partial t}\left(\frac{\phi s_{o}}{B_{o}}\right) \\
& \nabla \cdot\left[\frac{k k_{r w}}{B_{w} \mu_{w}}\left(\nabla p_{w}-\rho_{w} g \nabla D\right)\right]-\frac{q_{w}}{\rho_{w s c}}=\frac{\partial}{\partial t}\left(\frac{\phi s_{w}}{B_{w}}\right)
\end{aligned}
$$

In Formula (1):

$K$ : permeability; $K_{r o}, K_{r w}$ : relative water-oil permeability; $B_{o}, B_{w}$ : oil-water volume coefficient; $\mu_{o}, \mu_{w}$ oil-water viscosity; $\rho_{o}, \rho_{w}$ oil-water density; $\rho_{o s c} \rho_{\text {wsc }}$ : oil-water surface standard density; $P_{o}, P_{w}$ : oil-water pressure; $\Phi$ : porosity; $S_{o}, S_{w}$ : oil-water saturation; $q_{o}, q_{w}$ : flow rate of oil recovery, flow rate of water recovery; g. gravity; $D$ : calibration height; $\nabla \cdot$ : degree of diffusion; $\nabla$ : degree of Gradient.

Tracer concentration diffusion equation, as shown in Formula (2):

$$
Z \frac{\partial^{2} c}{\partial x^{2}}-u \frac{\partial c}{\partial x}=\frac{\partial c}{\partial t}
$$


In formula:

$Z$ : effective mixing coefficient; $C$ : tracer concentration; $X$ : one-dimensional length; $U$ : seepage velocity; $T$ : time.

Combined with the solution conditions, the concentration relationship formula is achieved, as shown in Formula (3):

$$
\frac{c(x, t)}{c_{0}}=\frac{1}{2} \operatorname{erfc}\left(\frac{x-u t}{2 \sqrt{Z t}}\right)
$$

$c_{0}$ : injection concentration; $\operatorname{erf}(x)$ : error function.

The wellbore concentration is the result of the mixing effect of the concentration produced on each streamline. Calculated formula as shown in Formula (4):

$$
c(t)=\int c_{0}(t-\tau(\psi)) q(\psi) \mathrm{d} \psi / \int q(\psi) \mathrm{d} \psi
$$

In formula:

$c(t)$ : output concentration of wellbore at a certain time; $c_{0}(t-\tau(\psi))$ : the output concentration corresponding to the wellbore position at the corresponding time on a certain streamline; $q(\psi)$ : the amount of fluid contribution on the streamline; $\int \mathrm{d}(\psi)$ : streamlined integration.

Tracer flows along the streamline, first-seeing point is in the position of water flooding front edge, and then flow into the wellbore to output, according to the law of flow, a water-front flow equation is established, as shown in Formula (5):

$$
x_{f}-x_{0}=\frac{f_{w}^{\prime}\left(S_{w f}\right)}{\phi A} \int_{0}^{t} q(t) \mathrm{d} t
$$

In formula:

$x_{\dot{f}}$ the leading edge in the two-phase seepage zone; $x_{0}$ : original oil-water interface position; $\varphi$ : porosity; $A$ : seepage flow area; $S_{w \dot{ }}$ water saturation of leading edge; $q(t)$ : the flow in time $t$.

According to the Formulas (1)-(5), combining the tracer information in Well A24 and the surrounding tracer information, the wave propagation factor of oil wells in Well A24 is calculated, as shown in Table 1.

Table 1. Water flooding and coefficient calculation results table of oil wells in A24 well group.

\begin{tabular}{cccccccc}
\hline $\begin{array}{c}\text { Injecting } \\
\text { well }\end{array}$ & $\begin{array}{c}\text { Monitoring } \\
\text { wells }\end{array}$ & $\begin{array}{c}\text { Well } \\
\text { spacing } \\
(\mathrm{m})\end{array}$ & $\begin{array}{c}\text { Tracer } \\
\text { seeing } \\
\text { time }(\mathrm{d})\end{array}$ & $\begin{array}{c}\text { Tracer } \\
\text { propulsion } \\
\text { speed }\left(\mathrm{m}^{3} / \mathrm{d}\right)\end{array}$ & $\begin{array}{c}\text { Peak } \\
\text { concentration } \\
(\mathrm{ppm})\end{array}$ & $\begin{array}{c}\text { Bottom } \\
\text { concentration } \\
(\mathrm{ppm})\end{array}$ & $\begin{array}{c}\text { Spread } \\
\text { factor }\end{array}$ \\
\hline \multirow{4}{*}{$\mathrm{A} 24$} & $\mathrm{~A} 14$ & 315 & 84 & 4.2 & 12.4 & 2 & 0.38 \\
& $\mathrm{~A} 15$ & 260 & 37 & 7.02 & 138.0 & 2 & 0.62 \\
& $\mathrm{~A} 16$ & 320 & 95 & 3.9 & 7.0 & 2 & 0.24 \\
& $\mathrm{~A} 23$ & 255 & 99 & 2.6 & 42.0 & 2 & 0.54 \\
& $\mathrm{~A} 25$ & 260 & 20 & 12.9 & 25.0 & 2 & 0.49 \\
\hline
\end{tabular}


According to Table 1, it can be seen that well A16 has the lowest spread factor which affected least by the well A24, it shows that the remaining oil around Well A16 is enriched, that means the direction around A16 well is the main potential direction.

\subsection{Quantitative Characterization of Remaining Oil Reserves Based on Potential Superposition Theory}

The fault of S sand body is well developed and the lateral distribution of sand body is small. There is remaining oil in the fault zone and the imperfect part of local well pattern. The longer the oil field is developed, the more refined the oil needs to be finely portrayed.

According to the mirror reflection method in seepage theory [16], the mirror reflection law of oil and water wells near the fault can be obtained. According to the potential superposition principle, any potential field distribution can be calculated. Take the $S$ oilfield one-injecting well with four oil wells pattern as an example, the formula for any potential is shown in Equation (6).

$$
\begin{aligned}
\Phi_{M} & =\frac{1}{2 \pi}\left(q_{h 1} \ln r_{1}+q_{h 2} \ln r_{2}-q_{h 3} \ln r_{3}+q_{h 4} \ln r_{4}+q_{h 5} \ln r_{5}\right)+C \\
& =\frac{q_{h 1}}{2 \pi} \ln \frac{r_{1} r_{2}^{\beta_{1}} r_{4}^{\beta_{3}} r_{5}^{\beta_{4}}}{r_{3}^{\beta_{2}}}+C
\end{aligned}
$$

The distribution of any potential field at the boundary is shown in Equation (7).

$$
\begin{aligned}
\Phi_{e} & =\frac{1}{2 \pi}\left(q_{h 1} \ln r_{e}+q_{h 2} \ln r_{e}-q_{h 3} \ln r_{e}+q_{h 4} \ln r_{e}+q_{h 5} \ln r_{e}\right)+C \\
& =\frac{q_{h 1}}{2 \pi} \ln r_{e}^{1+\beta_{1}-\beta_{2}+\beta_{3}+\beta_{4}}+C
\end{aligned}
$$

Formulas (6) and (7) are superposed to obtain pressure field formula at any point, as shown in Formula (8).

$$
P_{M}=P_{e}-\frac{q_{1} \mu}{2 \pi K h} \ln \frac{r_{e}^{1+\beta_{1}-\beta_{2}+\beta_{3}+\beta_{4}} r_{3}^{\beta_{2}}}{r_{1} r_{2}^{\beta_{1}} r_{4}^{\beta_{3}} r_{5}^{\beta_{4}}}
$$

In formula:

$\Phi_{M} \Phi_{e}$ : potential field for any point $\mathrm{M}$ to the boundary; $r_{1}-r_{5}$ : distance from well 1 to well 5 to point M; $r_{e}$ : the boundary point distance from well 1 to well 5 ; $q_{h 1}-q_{h 5}$ : thickness production or injection volume from well 1 to well 5 ; $C$ : integral constant.

Among:

$$
\beta_{1}=\frac{q_{h 2}}{q_{h 1}}, \beta_{2}=\frac{q_{h 3}}{q_{h 1}}, \beta_{3}=\frac{q_{h 4}}{q_{h 1}}, \beta_{4}=\frac{q_{h 5}}{q_{h 1}}
$$

By using Equations (6)-(8), the flow field in the sand body can be obtained by applying programming calculation, as shown in Figure 1.

It can be seen from Figure 1 that in the area near the fault and the imperfect well pattern, streamline did not affect or spread to a lesser extent. According to 


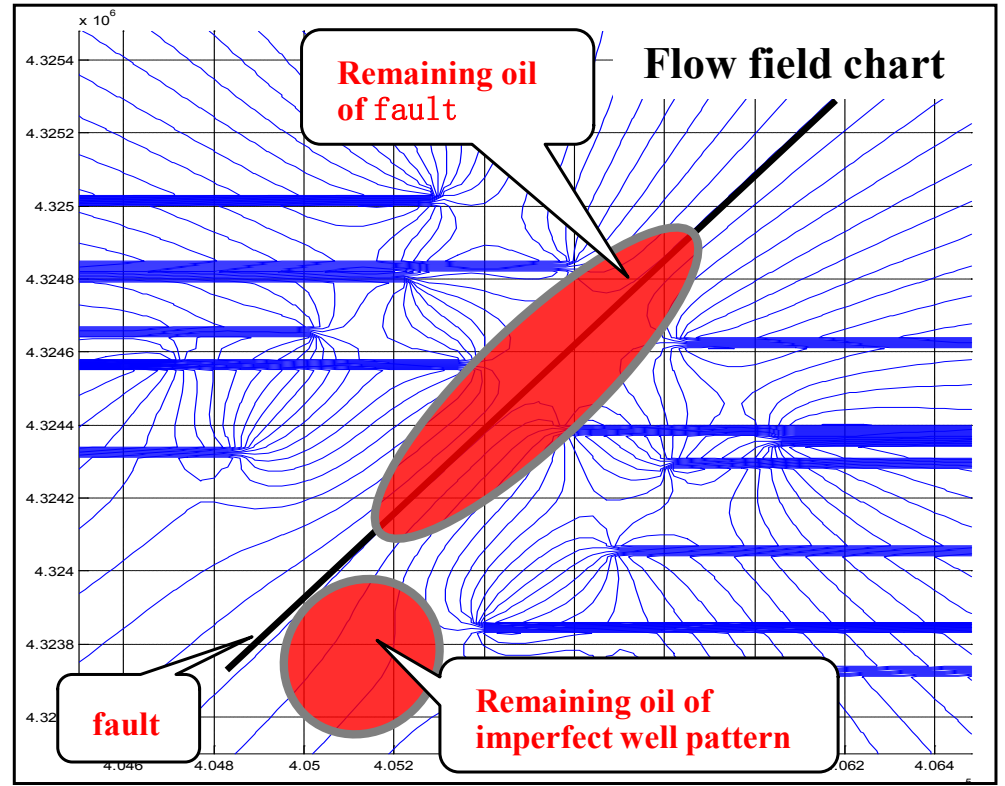

Figure 1. Flow field chart of Nm0-19 sand body.

the scope of the flow line, combined with the reserves calculation parameters, you can get the residual oil well near the fault and the imperfect area of the well. The remaining oil near the fault refers to the remaining oil near the fault, the imperfect remaining oil refers to the remaining oil of no wells in the well network in the sand body and the remaining oil in the area without the flow line. According to this method, the sand body of $\mathrm{S}$ oilfield is analyzed to calculate the remaining oil reserves in the fault zone and the imperfect area, as shown in Table 2 .

According to Table 2, the remaining oil reserves in the main sand body of $\mathrm{S}$ oilfield are $214.00 \times 10^{4} \mathrm{~m}^{3}$, which has the potential for excavation.

\subsection{Study on Multi-Method Validation of the Remaining Oil Fine Description}

Based on the study in Section 3.1, the residual oil enrichment around Well A16 can be judged according to the different water flooding and coefficient of oil well. According to the study of 3.2, it can be known that remaining oil exists near the fault and in the imperfect well pattern. According to the results of the study, the numerical simulation results are revised and recalculated to obtain the remaining oil saturation map in accordance with the law of dynamic change, as shown in Figure 2. As can be seen from Figure 2, there is a large amount of remaining oil in the area near the well A16, in the imperfect area and near the fault. Through the study of this paper, a variety of methods to verify each other to achieve the remaining refined oil refinement, while the remaining oil reserves can be quantified characterization, tapping the potential for the adjustment of wells to provide confidence. Through the mutual verification of multiple methods, the research on remaining oil refinement can be realized. At the same 


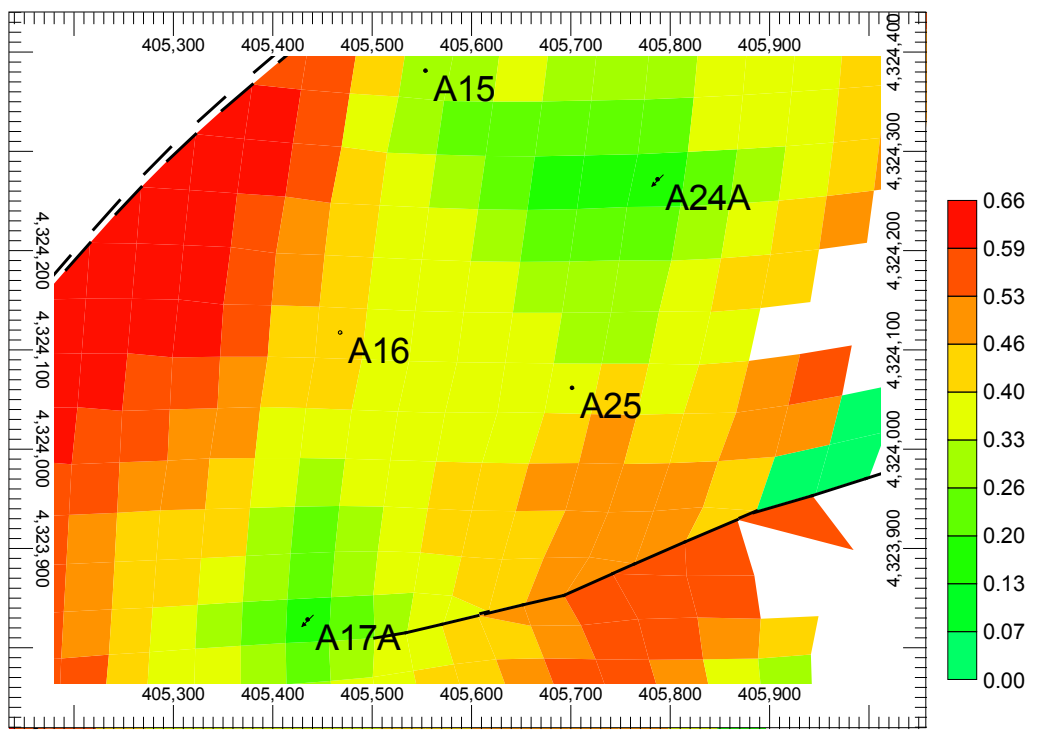

Figure 2. Remaining oil saturation of $\mathrm{Nm} 0-19$ sand body.

Table 2. S oilfield remaining oil reserves calculation results table.

\begin{tabular}{ccc}
\hline Sand body name & Remaining oil type & Remaining oil reserves $\left(10^{4} \mathrm{~m}^{3}\right)$ \\
\hline \multirow{2}{*}{ Nm0-19 } & Near the fault & 28.00 \\
Nm0-18+19 & Imperfect well pattern & 60.00 \\
& Imperfect well pattern & 70.00 \\
Nm0-26 & Near the fault & 13.00 \\
& Imperfect well pattern & 2.00 \\
Nm1-4 & Near the fault & 4.00 \\
& Imperfect well pattern & 7.00 \\
NmII-1 & Near the fault & 16.00 \\
& Imperfect well pattern & 14.00 \\
Total & - & 214.00 \\
\hline
\end{tabular}

time, the remaining oil reserves can be quantitatively characterized, which can provide confidence for potential through adjustment wells.

\section{Applications}

Through the research and mutual verification with the numerical simulation method, the description accuracy of remaining oil is improved, the remaining oil reserves and the distribution of remaining oil reserves are given, which can provide a reliable basis for the research of adjustment wells. According to the results, S oilfield has carried out 6 adjustment wells and has implemented 2 adjustment wells with good production effect, which confirms the reliability of the method in this paper. At the same time, in order to further reducing costs and increasing efficiency, this method has been applied with low-yield wells and shut-down wells, 3 side-drills has been put forward. Furthermore, based on the detailed study of residual oil, a well of adjustment wells drilled near the fault and 
no well-controlled residual oil-rich area has been proposed. Six adjustment wells have been studied in detail in the condition to realize stable production on the oilfield of low oil price, which meets economic evaluation requirements and increase oil recovery.

\subsection{The Reliability of This Study Confirmed by Two Adjustment Wells' Production}

This research has provided technical guidance for the implementation of horizontal adjustment wells called $\mathrm{A} 3 \mathrm{H}$ and $\mathrm{A} 33 \mathrm{H}$ in $\mathrm{Nm} 0-19$ and NmII-5+6 sub-layers of S oilfield respectively, and put into production in 2013. The production of the two wells is shown in Table 3.

It can be seen from Table 3 that the two adjustment wells have been put into operation to increase the daily oil production of $116 \mathrm{~m}^{3} / \mathrm{d}$, increase the recoverable reserves to $20.00 \times 10^{4} \mathrm{~m}^{3}$.

After putting into operation, the production effect of adjustment wells is better. Through production measurement, we can get production parameters such as daily oil production and water cut of adjustment wells. Take $\mathrm{A} 33 \mathrm{H}$ as an example, the initial water content of the well is low at only $5 \%$, and the daily oil yield after the production is $60 \mathrm{~m}^{3} / \mathrm{d}$ and the production is stable, as shown in Figure 3. The production of two adjustment wells is compared with the old oil well, as shown in Table 4.

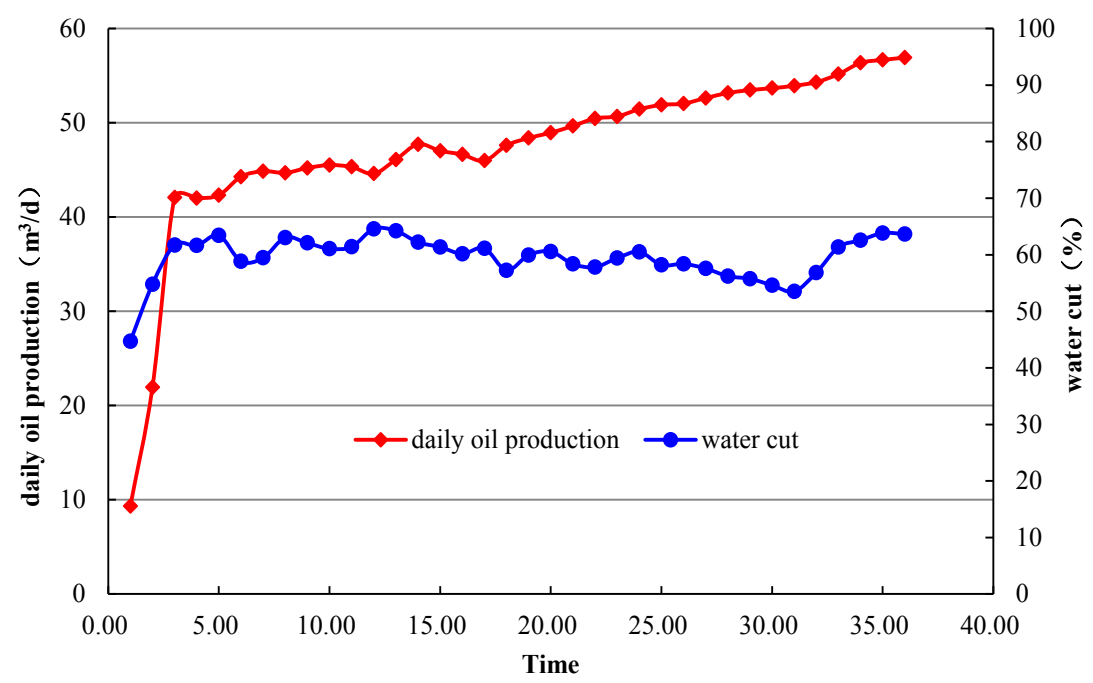

Figure 3. The production curve after adjustment wells $\mathrm{A} 33 \mathrm{H}$ put into operation.

Table 3. The table of two implemented adjustment wells' production statistics in S oilfield.

\begin{tabular}{cccc}
\hline Name & Drilling sand body & $\begin{array}{c}\text { Initial production }\left(\mathrm{m}^{3} / \mathrm{d}\right) \\
\text { capacity }\end{array}$ & $\begin{array}{c}\text { Design cumulative } \\
\text { oil production }\left(10^{4} \mathrm{~m}^{3}\right)\end{array}$ \\
\hline A3H & $\mathrm{Nm} 0-19$ & 56 & 8.80 \\
A33H & $\mathrm{NmII5+6}$ & 60 & 11.20 \\
\hline
\end{tabular}


Table 4. Comparison table of production situation on two adjustment wells and one old well in S oilfield.

\begin{tabular}{ccccc}
\hline name & $\begin{array}{c}\text { Initial production } \\
\text { capacity }\left(\mathrm{m}^{3} / \mathrm{d}\right)\end{array}$ & $\begin{array}{c}\text { Initial water } \\
(\%)\end{array}$ & $\begin{array}{c}\text { Design cumulative oil } \\
\text { production }\left(10^{4} \mathrm{~m}^{3}\right)\end{array}$ & Remarks \\
\hline A3H & 56 & 14 & 8.80 & adjustment well \\
$\mathrm{A} 33 \mathrm{H}$ & 60 & 5 & 11.20 & adjustment well \\
$\mathrm{A} 32 \mathrm{H}$ & 30 & 25 & 5.6 & old well \\
$\mathrm{A} 27 \mathrm{~S} 1$ & 50 & 8 & 6.8 & old well \\
\hline
\end{tabular}

In Bohai, the production parameters of each oil well will be measured every day. According to the measurement data, we can evaluate the production capacity and running dynamics of the oil well, and carry out appropriate adjustment measures to improve the effect of oil field development. It can be seen from $\mathrm{Ta}$ ble 4 that the initial production capacity, water cut and oil production are better than the produced well indicators which further confirms the reliability of the study method. Refinement of remaining oil description of the study can further improve the initial production capacity, the initial calculation of water and oil yield indicators accuracy of adjustment wells, so as to provide a favorable guarantee for the implementation of the adjustment well.

\subsection{Guidance Studies on Four Adjustment Wells and Implementation}

Through the production of two adjustment wells, it can be seen that the method has some reliability. According to this method, four adjustment wells have been studied according to the control of low-yield wells and shut-in wells in the oilfield: side-drills A16S1 with shut-down well A16, side-drills A7H1 with low-production wells A7M, drill A29 for well A29H1 and well A34 in the remaining oil-rich zone near the fault. The four adjustment wells are put into production in 2016. Initial daily increase production is $211 \mathrm{~m}^{3} / \mathrm{d}$, the four adjustment wells are expected to accumulate $23.82 \times 10^{4} \mathrm{~m}^{3}$.

Through the research in this paper, the remaining oil is described finely. In the oilfield, six adjustment wells have been studied. Six adjustment wells forecast to have accumulated oil accumulation of $43.82 \times 10^{4} \mathrm{~m}^{3}$. Improving oil recovery at the same time saving low-yield wells and shutting down the wells will achieve the purpose of reducing costs and increasing efficiency.

\section{Conclusions}

1) Based on the dynamic data of tracer, through tracer theory and seepage theory, innovatively proposed the application of water flooding spread factor method quantitatively and achieve the water flooding spread factor of A24 well group in $\mathrm{S}$ oil field to confirm the potential.

2) Application of mirror reflection method and potential superposition method to establish a pressure formula at any point in the one injection and four 
production well pattern, draw the flow field graph, and quantitatively evaluate the residual oil near the faults and the imperfect well pattern in the $S$ oilfield to determine the remaining oil reserve $\left(214.00 \times 10^{4} \mathrm{~m}^{3}\right)$, which provides material basis for potential of the remaining oil in the $S$ oilfield.

3) According to this paper, six adjustment wells has been proposed in S oilfield, the total oil production of 6 adjustment wells will increase $43.82 \times 10^{4} \mathrm{~m}^{3}$, and improve the effect of oilfield development.

4) This research provides a detailed description method of remaining oil in the high water cut stage of Bohai heavy oilfield which may provide some guidance for improving the recovery rate.

\section{Conflicts of Interest}

The authors declare no conflicts of interest regarding the publication of this paper.

\section{References}

[1] Ma, K.Q., Liu, Y.X. and Su, Y.C. (2013) Productivity Evaluation of Infill Well at High Water Cut Stage in S Oilfield, Bohai Bay. Fault-Block Oil \& Gas Field, 20, 71-73.

[2] Jiang, W.J., Wen, Z.H., Jiang, J., et al. (2013) Research on Stable Production Techniques in the High Water Cut Stage of CB Oilfield. Drilling \& Production Technology, 36, 64-67.

[3] Guo, T.X., Wang, S.M. and Wang, W.M. (2005) Comprehensive Adjustment of Development in Chengbei Oilfield. China Offshore Oil and Gas, 17, 312-315.

[4] Qu, Y.Z. (2011) Thickened Oil Water Plugging Technology Application in Reservoir North Block jin 16 in the Floor. Inner Mongolia Petrochemical Industry, 37, 263-264.

[5] Hu, Z.H., Yang, Q.H., Shen, C.S., et al. (2013) Distribution Rule and Development Strategy of Remaining Oil at the High Water-Cut Stage in Heavy Oilfield: Taking SZ Oilfield in Bohai Bay as an Example. Fault-Block Oil \& Gas Field, 20, 748-751.

[6] Wu, Z.M. (2010) The Research of Optimization Technology for Injection-Production Structure on High Water Cut Stage in Heavy Oil Field. Daqing Petroleum Institute, 27-54.

[7] Lv, G.X., Zhang, J., Liu, D.W., et al. (2010) Research on Technology of Enhance Water Drive Recovery Factor in High Watered Oilfield. Drilling \& Production Technology, 33, 55-57.

[8] Liu, Y.G., Xu, W.J. and Jiang, W.D. (2014) Study of Flooding Technology for Offshore Oilfields Pipelines. Oil Technology BBS, 33, 41-44.

[9] Li, H.S. (2015) Research and Application of Technology of Water Detection and Plugging for Horizontal Wells in Liaohe Oilfield. Sino-Global Energy, No. 4, 58-61.

[10] Hu, H. (2016) Adjustment Measures of Remaining Oil Tapping Based on Sand Body Structure. Lithologic Reservoirs, 28, 113-120.

[11] Zou, Y. and Han, X.Y. (2017) Fu 18 Block Tapping Remaining Oil Research. Petrochemical Industry Application, 36, 40-42.

[12] Lou, X.J. and Qiao, H.S. (2016) Development Strategy of Residual Oil in Complex 
Reservoir. Petrochemical Industry Technology, 3, 179-180.

[13] Guan, B.L. (2016) Study on Technology of Tapping the Remaining Oil in Late Stage of Huan 8 Block Development. Petrochemical Industry Technology, 4, 44.

[14] Li, M. (2009) Application of Cross-Hole Tracer Agent Monitoring Technology in Jianghan Oil Region. Journal of Jianghan Petroleum University of Staff and Workers, 22, 45-48.

[15] Chang, S.-M. (2014) Application of Cross-Hole Tracer Agent Monitoring Technology in Waterflood Development. Liaoning Chemical Industry, 43, 1059-1062.

[16] Li, X.P. (2008) The Underground Oil and Gas Percolation Mechanics. Petroleum Industry Press, Beijing, 61-84. 